Rapid Reviews COVID-19

\title{
Review 1: "COVID-19 and (Un)Desired Fertility: The Effect of Stay-at-Home Orders on Abortions in Mexico City"
}

Published on: Nov 29, 2020

DOI: $10.1162 / 2 \mathrm{e} 3983 f 5.125 \mathrm{be} 06 \mathrm{f}$

License: Creative Commons Attribution 4.0 International License (CC-BY 4.0). 


\section{$\underline{\text { RR:C19 Evidence Scale rating by reviewer: }}$}

- Potentially informative. The main claims made are not strongly justified by the methods and data, but may yield some insight. The results and conclusions of the study may resemble those from the hypothetical ideal study, but there is substantial room for doubt. Decision-makers should consider this evidence only with a thorough understanding of its weaknesses, alongside other evidence and theory. Decisionmakers should not consider this actionable, unless the weaknesses are clearly understood and there is other theory and evidence to further support it.

$* * * * * * * * * * * * * * * * * * * * * * * * * * * * * * * * * * * * * * *$

\section{Review:}

This paper analyzes the impact of stay-at-home orders on the reported numbers of legal abortions in Mexico City during the COVID-19 pandemic. It does so by using a difference-in-difference study design.

While there is a lot that is potentially interesting in this paper, and it is potentially informative, I am confused about the methodological approach. The study claims to do a difference-in-difference study but instead effectively what it does is compare abortions by week of the year in 2020 to those in the same weeks in year prior. A key assumption in the difference-in-difference approach is that the only thing that changed was the treatment but given that they are comparing different years of data, I think it is hard to justify this assumption. I don't understand how one can even check the parallel trends assumption with your post-treatment data.

I also think the authors need to be clear about the status of legal versus illegal abortions in Mexico. What are the alternatives to legal abortion in Mexico? Can the authors rule out that there were not increases in the rate of use of emergency contraception during lockdown? I have seen reports from across Latin America that there was a surge in demand for such products during COVID-19.

I recently reviewed another paper that suggested that Mexico City is a destination city for women across Latin America to seek abortions. What type of travel restrictions were implemented in Mexico City at the same time? Might this have affected the number of abortions? What fraction of abortions were among women who live outside of Mexico City? Could the reductions in abortions be due to decreased demand by non- 
Mexican women?

The authors make bold claims about the fact that these abortions are likely to be unwanted but do not really provide evidence to suggest that the demand for children had not been altered during the pandemic.

It is my recommendation that this study is rejected at this time. 